NBER WORKING PAPER SERIES

\title{
VIRTUOUS CIRCLES OF PRODUCTIVITY: \\ STAR BIOSCIENTISTS AND THE \\ INSTITUTIONAL TRANSFORMATION OF INDUSTRY
}

\author{
Lynne G. Zucker \\ Michael R. Darby \\ Working Paper 5342
NATIONAL BUREAU OF ECONOMIC RESEARCH
1050 Massachusetts Avenue
Cambridge, MA 02138
November 1995

An earlier version of this paper was presented at the National Academy of Sciences "Colloquium on Science, Technology, and the Economy," Irvine, CA, October 20-22, 1995. It builds on an ongoing project in which Marilynn B. Brewer also long played a leading role. Jeff Armstrong was responsible for the analysis of firm success and Maximo Torero for the analysis of mobility of top scientists. This research has been supported by grants from the Alfred P. Sloan Foundation through the NBER Research Program on Industrial Technology and Productivity, the National Science Foundation (SES 9012925), the University of California Systemwide Biotechnology Research and Education Program, the University of California Systemwide Pacific Rim Research Program, the UCLA Center for American Politics and Public Policy, and the UCLA Institute of Industrial Relations. We acknowledge very useful comments from David Butz, Woon Gyu Choi, Harold Demsetz, Erwin Diewert, Robert Drazin, Martin Feldstein, Mark Grady, Zvi Griliches, Keith Head, Rebecca Henderson, Adam Jaffe, Benjamin Klein, Josh Lerner, Marvin B. Lieberman, Richard R. Nelson, Gary Pisano, Jeff Rosensweig, L.G. Thomas, Ivo Welch, John Fred Weston and participants in seminars and presentations at the M.I.T. Sloan School, the 1995 NBER Summer Institute on Productivity, the 1994 Stanford Conference on Trust in Organizations, UCLA Business Organization and Regulation Workshop, the UCLA Seminar on Pharmaceutical Economics and Policy, and the 1993 West Coast Conference on Small Group Research. We are indebted to a remarkably talented team of post-doctoral fellows Zhong Deng, Julia Liebeskind, and Yusheng Peng and research assistants Paul J. Alapat, Jeff Armstrong, Cherie Barba, Lynda J. Kim, Kerry Knight, Edmundo Murrugara, Amalya Oliver, Alan Paul, Jane Ren, Erika Rick, Benedikt Stefansson, Akio Tagawa, Maximo Torero, Alan Wang, and Mavis Wu. This paper is part of NBER's research program in Productivity. Any opinions expressed are those of the authors and not those of the National Bureau of Economic Research.

(c) 1995 by Lynne G. Zucker and Michael R. Darby. All rights reserved. Short sections of text, not to exceed two paragraphs, may be quoted without explicit permission provided that full credit, including $\odot$ notice, is given to the source. 


\title{
VIRTUOUS CIRCLES OF PRODUCTIVITY: STAR BIOSCIENTISTS AND THE \\ INSTITUTIONAL TRANSFORMATION \\ OF INDUSTRY
}

\begin{abstract}
The most productive ("star") bioscientists possessed intellectual human capital of extraordinary scientific and pecuniary value for some 10-15 years after Cohen \& Boyer's 1973 founding discovery for biotechnology. This extraordinary value was due to the union of still scarce knowledge of the new research techniques and genius and vision to apply these techniques in novel, valuable ways. As in other sciences, star bioscientists were particularly protective of their techniques, ideas, and discoveries in the early years of the revolution, tending to collaborate more within their own institution which slowed diffusion to other scientists. Therefore, close, bench-level working ties between stars and firm scientists were needed to accomplish commercialization of the breakthroughs. Where and when the star scientists were actively producing academic publications is a key determinant of where and when commercial firms began to use biotechnology. The extent of collaboration by a firm's scientists with stars is a powerful predictor of its success: for each 9 articles co-authored by an academic star and firm scientists, about 3 more products in development, 1 more on the market and 1550 more employees are estimated. Such collaboration with firms, or employment, also results in significantly higher rates of citation to articles written with the firm. The U.S. scientific and economic infrastructure has been particularly effective in fostering and commercializing the bioscientific revolution. To provide an initial indication of international competitiveness, we estimate stars' distribution, commercial involvement, and migration across the top 10 countries in bioscience. These results let us inside the black box to see how scientific breakthroughs become economic growth, and consider the implications for policy.
\end{abstract}

Lynne G. Zucker

Department of Sociology

University of California, Los Angeles

Los Angeles, CA 90095-1551

and NBER
Michael R. Darby

Anderson Graduate School of Management

University of California, Los Angeles

Los Angeles, CA 90095-1481

and NBER 


\section{Virtuous Circles of Productivity: Star Bioscientists and the Institutional Transformation of Industry}

"Technology transfer is the movement of ideas in people."

- Donald Kennedy, Stanford University, March 18, 1994

Scientific breakthroughs are created by, embodied in, and applied commercially by particular individuals responding to incentives and working in specific organizations and locations; it is misleading to think of scientific breakthroughs as disembodied information which, once discovered, is transmitted by a contagion-like process in which the identities of the people involved are largely irrelevant. In the case of biotechnology, as new firms were formed and existing firms transformed to utilize the new technology derived from the underlying scientific breakthroughs, the very best scientists were centrally important in affecting both the pace of diffusion of the science and the timing, location, and success of its commercial applications.

We, in work done separately and in collaboration with coauthors (1-6), are investigating the role of these "star" bioscientists (those with more than 40 genetic sequence discoveries or 20 or more articles reporting genetic sequence discoveries by 1990) and their "collaborators" (all coauthors on any of these articles who are not stars themselves) in biotechnology." The star scientists are extraordinarily productive, accounting for only 0.8 percent of all the scientists listed in GenBank through 1990 but 17.3 percent of the published articles; put differently their productivity was almost 22 times the average GenBank scientist.

Our prior research has concentrated on particular aspects of the process of scientific discovery and diffusion and of technology transfer. We draw here two broad conclusions from this body of work: (a) to understand the diffusion and commercialization of the bioscience breakthroughs, it is essential to focus on the scientific elite, the stars, and the forces shaping their behavior, and (b) the breakthroughs as embodied in the star scientists initially located primarily 
at universities created a demand for boundary spanning between universities and firms via star scientists moving to firms or collaborating at the bench science level with scientists at firms. We demonstrate empirically that these ties across university-firm boundaries facilitated both the development of the science and its commercialization, with the result that new industries were formed and existing industries transformed during 1976-1995.

We report below the following major findings from our research: Citations to star scientists increase for those who are more involved in commercialization by patenting and/or collaborating or affiliating with new or pre-existing firms (collectively, new biotech enterprises or NBEs). As the expected value of research increases, star scientists are more likely to collaborate with scientists from their own organization, and this within-organization collaboration decreases the diffusion of discoveries to other scientists. Incumbent firms are slow to develop ties with the discovering university stars, leading some stars to found new biotechnology firms to commercialize their discoveries. Star bioscientists centrally determined when and where NBEs began to use biotechnology commercially and which NBEs were most successful. Stars that span the university/NBE boundary both contribute significantly to the performance of the NBE and also gain significantly in citations to their own scientific work done in collaboration with NBE

scientists. Nations differentially gain or lose stars during the basic science- and industry-building period, indicating the competitive success of different national infrastructures supporting development of both the basic science and its commercial applications.

\section{Ideas in People}

There are great differences in the probability that any particular individual scientist will 
produce an innovation that offers significant benefits, sufficient possibly to outweigh the costs of implementing it. We know that a wide range of action differs between great scientists -including our stars -- and ordinary scientists, from mentoring fewer and brighter students to much higher levels of personal productivity as measured by number of articles published, number of citations to those articles, and number of patents $(5,9,10)$.

As shown in Table 1, among the 207 stars who have ever published in the U.S. we observe higher average annual citation rates to genetic-sequence-reporting articles, a scientific productivity measure, for stars with greater commercial involvement: most involved are those ever listing a NBE as one's affiliation ("affiliated stars"), next are those ever coauthoring with one or more scientists then-listing a local NBE as their affiliation ("local linked stars"), and then those listing only such coauthorship with NBE scientists outside their local area ("other linked stars" who are less likely to be working directly in the lab with the NBE scientists). ${ }^{b}$ We distinguish local from other on the basis of the 183 functional economic areas making up the United States (called "BEA areas" or BEAs because they are defined by the U.S. Bureau of Economic Analysis). In addition, being listed as discoverer on a genetic sequence patent implies greater commercial involvement. For the U.S. as a whole, stars affiliated with firms and with patented discoveries are cited over 9 times as frequently as their pure academic peers with no patents or commercial ties. The differences in total citations reflects both differences in the quantity of articles and their quality as measured by citation rate, where quality accounts for most of the variation in total citations across these groups of scientists.

Why Intellectual Human Capital? In most economic treatments, the information in a discovery is a public good freely available to those who incur the costs of seeking it out, and thus scientific discoveries have only fleeting value unless formal intellectual-property-rights 
mechanisms effectively prevent use of the information by unlicensed parties; i.e., absent patents, trade secrets, or actual secrecy, the value of a discovery erodes quickly as the information diffuses.

We have a different view: Scientific discoveries vary in the degree to which others can be excluded from making use of them. Inherent in the discovery itself is the degree of "natural excludability:" if the techniques for replication involve much tacit knowledge and complexity and are not widely known prior to the discovery -- as with the 1973 Cohen-Boyer discovery (11) -then any scientist wishing to build on' the new knowledge must first acquire hands-on experience. High-value discoveries with such a high degree of natural excludability, so that the knowledge must be viewed as embodied in particular scientists' "intellectual human capital," will yield supranormal labor income for scientists who embody the knowledge until the discovery has sufficiently diffused to eliminate the quasi-rents in excess of the normal returns on the cost of acquiring the knowledge as a routine part of a scientist's human capital..$^{\mathrm{c}}$

Thus, we argue that the geographic distribution of a new science-based industry can importantly derive from the geographic distribution of the intellectual human capital embodying the breakthrough discovery upon which it is based. This occurs when the discovery -- especially an "invention of a method of discovery" (12) -- is sufficiently costly to transfer due to its complexity or tacitness (13-17) so that the information can effectively be used only by employing those scientists in whom it is embodied.

Scientific Collaborations. Except for initial discoverers, the techniques of recombinant DNA (rDNA) were generally learned by working in laboratories where they were used, and thus diffusion proceeded slowly, with only about a quarter of the 207 U.S. stars and less than an eighth of the 4004 U.S. collaborators in our sample ever publishing any genetic-sequence 
discoveries by the end of 1979 . In a variety of other disciplines, scientists use institutional structure and organizational boundaries to generate sufficient trust among participants in a collaboration to permit sharing of ideas, models, data, and material of substantial scientific and/or commercial value with the expectation that any use by others will be fairly acknowledged and compensated to the contributing scientists (8).

Zucker, Darby, Brewer, and Peng (1) relate the collaboration network structure in biotechnology to the value of the information in the underlying research project: the more valuable the information, the more likely the collaboration is confined to a single organization. As expected, diffusion slows as the share of within-organization collaborations increases, so organizational boundaries do operate to protect valuable information effectively. In work underway, we replicate in Japan: the value of information being produced increases the probability that collaborators come from the same organization.

Boundary Spanning Between Universities and NBEs. This work on collaboration structure indicates the importance of organizational boundaries in serving as "information envelopes" that can effectively limit diffusion of new discoveries, thereby protecting them. It follows that when information transfer between organizations is desired, boundary spanning mechanisms are vital, creating a demand for social structure that produces ties between scientists across these boundaries. In biotechnology, early major discoveries were made by star scientists in universities but commercialized in NBEs, so the university-firm boundary was the crucial one. It is "people transfer, " not technology transfer, that is measured as star scientists who become affiliated with or linked to NBEs. Working together on scientific problems seems to provide the best "information highway" between discovering scientists and other researchers.

New institutions and organizations, or major changes in existing ones, that facilitate the 
information flow of basic science to industry are positive assets, but also require considerable redirection of human time and energy, and therefore incur real costs $(1,18)$; some also require redirection of substantial amounts of financial capital. Therefore, for social construction to occur, the degree to which these structures facilitate bioscience and its commercialization must outweigh the costs.

If the endowed supply of institutions and organizations have not already formed strong ties between universities or research institutes and potential NBES, or at least make these ties very easy to create, then demand for change in existing structures and/or formation of new institutions and organizations to facilitate these ties is expected. ${ }^{d}$ How much structure is changed, and how much is created, will depend on the relative costs and benefits of transformation/formation.

In the U.S. the costs relative to the benefits of transforming existing firms appear to be higher than those incurred in forming new firms: Over 1976-1990, 74 percent of the enterprises beginning to apply biotechnology were ad-hoc creations, so-called new biotech firms (NBFs), compared to 26 percent representing some transformation of the technical identity of existing firms (new biotech subunits or NBSs). As Table 2 shows, ties of star scientists to NBSs have emerged slowly in response to the demands for strong ties between universities or research institutes and firms, accounting for under seven percent of the articles produced by affiliated or linked stars through 1985 and only increase to about 13 percent in the $1986-90$ time period. $^{e}$ The resistance of pre-existing firms to transformation is understated even by these disproportionately low rates, since the NBSs have generally many more employees than NBFs and since the majority of incumbent firms in the pharmaceutical and other effected industries had not yet begun to use biotechnology by 1990 and so are not included in our NBS count. 
At the same time, many of the NBFs were literally "born" with strong ties to academic star scientists, who were often among their founders. Through 1990 , generally much smaller and less well capitalized NBFs produced more research articles with affiliated or linked stars than the NBSs.

\section{Commercialization of Bioscience}

NBE Entry. The implications of our line of argument are far reaching. An indicator of the demand for forming or transforming NBEs to facilitate commercialization is the number of star scientists in a local area. Absent such demand measures, the local and national economic infrastructure provide a good basis for prediction; but, when stars (and other demand-related indicators) are taken into account, most effects of the economic infrastructure disappear (4).

Our empirical analysis of NBE entry is based on panel data covering the years 1976-1989 for each of the 183 BEA areas. Key measures of local demand for birth of NBEs are the numbers of stars and collaborators active in a given BEA in a given year. We define a scientist as active where and when our star-article data base shows him or her to have listed affiliation in the BEA on three or more articles published in that or the two prior years. This is a substantial screen, with only 135 of the 207 U.S.-publishing stars ever active in the U.S. while only 12.5 percent (500 out of 4004 ) U.S.-publishing collaborators are ever active in the U.S.

We motivate the general analysis frame selected by plotting both ever- active star scientists and NBEs on a map of the U.S. cumulatively through 1990 (Fig. 1). We can see that the location of stars remained relatively concentrated geographically even when considering all those born in the whole period, and that NBEs tended to cluster in the areas with stars. The 
geographic concentration and correlation of both stars and NBEs is even greater for those entering by 1980 .

With this very simple analysis, we can see the strong relationship between the location of ever-active stars and NBEs. Table 3 further explores this relationship using our panel data. The "count" variable of births of NBEs requires a poisson model, a simple "at risk" model that views the following agents in a BEA area as potentially starting an NBE: active stars and collaborators, other significant scientists working in related technologies (proxy measures: number of universities with top quality bioscience departments and number of bioscientists in the area supported by federal grants), and venture capital firms located in the BEA. Other measures of the economic infrastructure's support for exploiting the value of the local science besides venture capital firms include variables at local (earnings per job for local labor quality and overall employment levels) and national (cost of capital) levels.

The models explore separately the demand for NBEs (model a) and the economic infrastructure for developing the industry (model b), and then examine the combined effects (model c). In model a, we find that there is a significant effect of stars, but not of collaborators, on the probability of founding a NBE, but that the effects are non-linear for stars as indicated by the significant squared term. By examining the later time period of $1986-89$, we find that the positive effect of stars is virtually cancelled out while there is a significant positive effect from their collaborators who may be providing labor to new enterprises. Also in model a, we see that the number of universities with top-quality biotechnology-relevant departments and the number of biotechnology-relevant faculty supported by federal grants in the local area are also significant indicators of demand for NBEs. We included these measures as proxies for the faculty involved in important biotech-relevant, but non-rDNA specific, science. 
In model $b$, we examine the effects of economic infrastructure on the probability of an NBE being formed or transformed, and find that the number of venture capital firms in the area, total employment, and average earnings all increase NBE formation; the cost of capital, indicated by the earnings/price ratio for the Standard \& Poors 500 index, has the expected sign but is not significant.

In the combined model $\mathrm{c}$, there is only a small increase in explanatory power as measured by the logarithm of the likelihood function when the economic infrastructure variables are added to the intellectual capital variables. Overall, the measures of demand for NBEs maintain their significance, but the measures of economic infrastructure show a more varied pattern. Most strikingly, venture capital retains its significance, but becomes negative. We interpret this reversal to indicate that venture capital, while possibly lowering the effective cost-of-capital for firms born close to them and improving their management through aggressive oversight and thus generally increasing local commercialization, may at the same time lead to packaging of an area's intellectual human capital resources into fewer, larger firms that can go public more rapidly.

NBE Success and Ties to Star Scientists. The practical importance for successful commercialization of an intellectual human capital bridge between universities and firms is confirmed in a cross-section of 76 California NBEs (5). Local linked (and sometimes affiliated) stars have significant positive effects on a variety of NBE success measures: ${ }^{f}$ that is, the NBEs most likely to form the nucleus of a new industry are those that have the strongest collaborative links with star scientists. We will see below that these NBE-star ties also dramatically improve the scientists' productivity. This remarkable synergy, along with the intrinsic and financial incentives it implies aligns incentives across basic science and its commercialization in a manner not previously identified. 
We first focus on one measure of NBE success here: number of products in development, coded from Bioscan 1989. We then briefly review the largely consistent results for products on the market and employment growth. ${ }^{\mathrm{g}}$

To provide an intuitive feel for our results, the map in Fig. 2 shows both the location of star scientists and the location of enterprises that are using biotechnology methods. Note that we limited this initial work to California, because of the intensive data collection required. California saw early entry into both the science and industry of biotechnology, possesses a number of distinct locales where bioscience or both the science and industry have developed, and is generally broadly representative of the U.S. biotechnology industry. ${ }^{b}$ Large dots in circles indicate NBE-affiliated or NBE-linked stars, while large dots alone indicate stars located in that area but not affiliated nor linked with a local firm. We indicate the location of firms by either scaled triangles, representing NBEs with no linked or affiliated stars, or by scaled diamonds, representing NBEs with linked and/or affiliated stars. The size of the triangle or diamond indicates the number of products in development; small dots represent NBEs with no products in development. While there is a small diamond and there are a few large triangles, it is clear that generally NBEs with linked and/or affiliated stars are much more likely to have many products in development.

In Table 4 these basic results are explored more fully in a cross-sectional analysis at the firm level, while adding two additional measures of success: number of products on the market drawn from Bioscan 1989 and employment growth between 1989 and 1994 based on a telephone survey with a response rate of 79 percent and only 3 refusals (see 5 for more detail). Looking across the regressions, untied stars (those neither affiliated nor linked to a firm) either have no effect on firm success, or for number of products on the market have a negative effect. The lack 
of positive effect predicted in our approach differs sharply from prior economic treatments: All scientists -- star and non-star, tied or non-tied -- have been pooled together to examine knowledge spillovers, defined as the positive externalities of scientific discoveries on productivity of firms which neither made the discovery themselves nor licensed its use from the holder of intellectual property rights.'

Most important for our theoretical approach, the effects of the number of articles written by academic stars when linked to NBE-scientists are uniformly positive and significant. To provide an intuitive feel for the magnitude of these effects, about one more product in development results from every three articles that a linked university star scientist co-authors with NBE scientists, and 9 articles result in one more product on the market. There are about 170 more employees added over 1989-1994 for each article with a linked university star. ${ }^{j}$ We note two qualifications to these strong findings: (a) It is not the articles themselves. but the underlying collaborations whose extent is indicated by the number of articles which matters. (b) Correlation cannot prove causation, but we do have some evidence that the main direction of causation runs from star scientists to the success of firms and not the reverse. ${ }^{k}$

The NBE-affiliated stars, however, show a more mixed pattern, with a significant effect estimated only for products on the market. A smaller effect than for NBE-linked stars might be explained by the boundary-spanning argument, but the coefficient should be robustly significant and positive. We think that the high correlation between the presence of NBE-affiliated and NBE-linked stars -- with the affiliated stars possibly recruiting involvement by linked academic stars -- may obscure the relationship. Indeed, in other specifications of the model predicting products in development not presented in Table 4, NBE-affiliated stars are significant as long as NBE-linked stars are omitted from the equation. 
We control for three firm characteristics in Table 4. First, NBFs have significantly more products in development and significantly fewer products on the market; there was no significant effect on employment growth. From case study data $(2,6)$, we expected that NBFs would be more likely to report products in development because their financial "burn rate" requires outside capital that will be based primarily on the promise of forthcoming products. NBSs, absent such fund-raising demands, are more likely to keep such information proprietary while at the same time being more likely to combine various kinds of pre-existing expertise to bring products to the market more rapidly.

Second, NBE age is positively related to both products in development and products on the market, because of the significant lags especially if the products are pharmaceuticals, but not to employment growth. Third, if a NBE uses rDNA technologies, it has significantly more products in development, fewer products on the market, and higher employment growth. The pattern of results is also consistent with most rDNA technologies focused on pharmaceuticals, with their very high promise but lengthy approval process.

Star Scientist Success and Ties to NBEs. We have seen how ties to stars predict more products in development and on the market, as well as more employment growth. Just as ties predict NBE success, they also predict higher level of scientific success as measured by citations. Recall the strong covariation between total citations and the degree to which stars are involved in commercialization and patenting in Table 1. It can be explained in three, possibly complementary ways: (a) The stars who are more commercially involved really are better scientists than those who are not involved either because they are more likely to see and pursue commercial applications of their scientific discoveries or are the ones most sought out by NBEs for collaboration or venture capitalists to work on commercial applications (quality-based 
selection). (b) For this elite group there is really no significant variation across stars in the expected citations to an article, but NBEs and venture capitalists make enormous offers to the ones lucky enough to have already made one or more highly cited discoveries (luck-based selection). (c) NBEs provide more financial and other resources to scientists who are actively working for or in collaboration with the firm making it possible for them to make more progress (resource/productivity).

The first explanation would predict that NBEs benefit from the very best scientists, but these stars are equally productive whén they are not working with firms. The second explanation implies that the stars who work with firms have higher citation rates before working with the firm than during and afterwards. Finally, the third explanation implies that NBEs actually increase the quality of the stars' scientific work so that their publications written at or in collaboration with a NBE would be more highly cited than those written either before or afterwards.

Because we have the star scientists' full publishing histories for articles reporting geneticsequence discoveries (up to April 1990), we can competitively test these three explanations of the higher citation rates observed for stars who are more involved in commercialization by looking at the total citations received by each of these articles for 1982, 1987, and 1992 (mean $=14.52$ for the world and 16.64 for the U.S.). OLS regression estimates are reported in Table 5 for both the full sample of all articles and a subsample restricted to those that have a star author located in the U.S. Since most articles have only 1 star author (mean $=1.37$ for the world and 1.30 for the U.S.), we focus on that case only.' Suppose also, as is nearly always the case, that a particular star is affiliated with or linked to at most one NBE.

For stars that are completely untied to firms, the first six variables (not counting the constant) are always zero and the remaining four control variables are the only ones entering. 
For the stars who are ever affiliated, PREAF $=1$ and STARAF $=$ POSTAF $=0$ on publications prior to their affiliation, PREAF $=0$ and STARAF $=$ POSTAF $=1$ on publications during their affiliation, and PREAF $=\mathrm{STARAF}=0$ and POSTAF $=1$ on publications after their affiliation. In terms of the three polar hypotheses, quality-based selection predicts PREAF, POSTAF $>0$ $\&$ STARAF $=0$; luck-based selection implies PREAF $>0 \&$ STARAF $=$ POSTAF $=0$; and the resource/productivity argument implies STARAF $>0, \mathrm{PREAF}=\mathrm{POSTAF}=0$. A similar pattern holds for linked stars if PREAF, STARAF, and POSTAF are replaced with the PRELK, COLAF, and POSTLK variables, respectively.'

The results in Table 5 provide very strong support for the resource/ productivity hypothesis for affiliated stars: the presence of one or more affiliated stars about doubles the expected citations received by an article. The same hypothesis is supported for (local-, other-, and foreign-NBE) linked stars in the full sample, but the combination of moderately lower coefficient and higher standard-error estimates makes COLAF insignificant in the U.S.-only sample. There is also evidence that highly-cited academic scientists are selected by NBEs for collaborations in the full sample, but this does not hold up in the U.S. sample nor is PREAF significant in either sample. The pure quality hypothesis is contradicted by the insignificant (and negative) coefficients on POSTAF and POSTLK in both samples. The four control variables do not present any puzzles so discussion of them is omitted here.

International Competitiveness and Movement of Stars. Our syllogism argues that star scientists embodying the breakthrough technology are the "gold deposits" around which new firms are created or existing firms transformed for an economically significant period of time, that firms which work with stars are likely to be more successful than other firms, and that -although access to stars is less essential when the new techniques have diffused widely -- once 
the technology has been commercialized in specific locales, internal dynamics of agglomeration $(25,34-36)$ tend to keep it there. The conclusion is that star scientists play a key role in regional and national economic growth for advanced economies, at least for those science-based technologies where knowledge is tacit and requires hands-on experience.

Given the widespread concern about growth and "international competitiveness," we present in Table 6 comparative data for the top ten countries in biotechnology on the distribution, commercial involvement, and migration of star scientists. Based on country-by-country counts of stars who have ever published there, the U.S. has just over half of the world's stars. Our nearest competitor, Japan, has only one fourth as many. Collectively, the North American Free Trade Area has 55.7\%, the European Community and Switzerland $27.4 \%$, and Japan and Australia $16.9 \%$ of the stars operating in the top 10 countries.

Looking at the fraction of stars who are ever affiliated with or linked to a NBE in their country, we see that the U.S. particularly, as well as Japan, Switzerland, Netherlands, and Belgium all appear to have substantial star-involvement in commercialization, with more limited involvement in the U.K. and Australia. Surprisingly, at least up to 1990 when our data base currently ends, we find no evidence of these kinds of "working" commercial involvement by stars in France, Germany, or Canada. ${ }^{n}$ Both the large number of the best biotech scientists working in the U.S. and their substantial involvement in its commercialization appear to interact in explaining the U.S. lead in commercial biotechnology. These preliminary findings lend some support to the hypothesis that boundary-spanning scientific movement and/or collaboration is an essential factor both in the demand for forming or transforming NBEs and in determining their differential success. In work underway, we are modeling empirically the underlying mechanisms which explain each of these proximate determinants. 
Migration is a particularly persuasive indicator of the overall environment -- scientific and commercial -- faced by these elite bioscientists: Moving across national boundaries involves substantial costs so that differences in infrastructure must be correspondingly large. The U.S., with a strong comparative advantage in the higher education industry as well as many of the key discoveries, is the primary producer of star scientists in the world. Despite the significant outflow of outstanding young scientists who first publish in the U.S. before returning home, America has managed to attract enough established stars to achieve a small net in-migration. ${ }^{\circ}$ The major losers of key talent have been Switzerland, the U.K., and Canada. Field work has indicated that Swiss cantons have enacted local restrictions inhospitable to biotechnology and that the U.K. has systematically reduced university support (37) and deterred other entrepreneurial activity by subsidy to favored NBEs. The Canadian losses presumably reflect the ease of mobility to the particularly attractive U.S. market.

\section{Conclusions}

Generalizability. We have seen for biotechnology that a large number of new firms have been created and pre-existing businesses transformed in order to commercialize revolutionary breakthroughs in basic science. ${ }^{p}$ Economic and wage growth in the major research economies are dependent upon continuing advances in technology, with the economies' comparative advantages particularly associated with the ability of highly skilled labor forces to implement new breakthrough technologies in a pattern of continuous renewal $(23-25,38,39)$. Based on extended discussions with those familiar with other technologies and some fragmentary evidence in the literature, it seems likely that many of our central findings do generalize to other cases of major 
scientific breakthroughs which lead to important commercial applications.

First note that technological opportunity and appropriability -- the principal factors that drive technical progress for industries $(40,41)$-- are also the two necessary elements that created extraordinary value for our stars' intellectual human capital during the first decade of biotechnology's commercialization. While relatively few mature industries are driven by technological opportunity in the form of basic scientific breakthroughs, the emergence phase of important industries frequently is so driven.

For example, Kogut, Walker, Shan, and Kim (42) find broadly similar patterns of interfirm relationships for large and small enterprises within and across national boundaries for semiconductors and biotechnology, although they argue and point to some corroborating evidence that embodiment of technology in individual scientists is even more important for semiconductors than for biotechnology. Levin (43) notes that [as with rDNA products] integrated circuits were initially nearly impossible to patent. More generally, Balkin and Gomez-Mejia (44) report on the distinctive emphasis on incentive pay and equity participation for technical employees in (largely non-biotech) high-tech firms, especially for the "few key individuals in research and development ... viewed as essential to the company..." Success in high-technology, especially in formative years, we believe comes down to motivated services of a small number of extraordinary scientists with vision and mastery of the breakthrough technology.

Growing Stars and Enterprises. We have seen for biotechnology -- and possibly other science-driven breakthrough technologies -- that the very best scientists play a key role in the formation of new and transformation of existing industries, profiting scientifically as well as financially. We see across countries that there is very substantial variation in the fraction of star scientists involved in commercialization, bringing discoveries initially from the universities to the 
firms via moving or working with NBE scientists. Clearly, there are very substantial implications for economic growth and development involved in whether a nation's scientific infrastructure leads to the emergence of numerous stars and is conducive to their involvement in the commercialization of their discoveries. ${ }^{9}$

Commercialization is more a traffic rotary than a two-way street: More commercialization yields greater short-run growth, but this may be offset in the future if the development of basic science is adversely affected. Commercial involvement of the very best scientists provides them greatly increased resources and is associated with increased scientific productivity as measured by citations. However, it may lead them to pursue more commercially valuable questions, passing up questions of greater importance to the development of science. On the other hand; the applied questions of technology have often driven science to examine long-neglected puzzles which lead to important advances and indeed important new subdisciplines such as thermodynamics and solid-state physics.

We are confident that the commercial imperative will continue to a play an important role in both private and public decision making. We believe that it is essential, therefore, that we develop a better understanding of what policies, laws, and institutions account for the wide variety of international experience with the science and commercial application of biotechnology, and their implications, for better or worse, for future scientific advancement.

Both field and quantitative work have taught us technology transfer is about people, but not just "ideas in people." The "people transfer" that appears to drive commercialization is importantly altered by the by the incentives available and by the entrepreneurial spirit that seeks "work arounds" in the face of impediments. A star scientist who can sponsor a rugby team at Kyoto University seems capable of achieving anything, but we also see that different rules, laws, 
resources, and customs have led to wide national differences in success in biotechnology. We need deeper empirical understanding of these institutional determinants of personal and national achievement in a variety of sciences and technologies in order to retain what is valuable and replace what is not. The most important lessons are to be drawn not for analysis of past breakthroughs which have formed or transformed industries, but for those yet to come in sciences we can only guess. 


\section{REFERENCES}

1. Zucker, Lynne G., Michael R. Darby, Marilynn B. Brewer, and Yusheng Peng, "Collaboration Structure and Information Dilemmas in Biotechnology: Organizational Boundaries as Trust Production, " in Roderick M. Kramer and Thomas Tyler, eds., Trust in Organizations, Newbury Park, CA: Sage, 1995 in press.

2. Liebeskind, Julia Porter, Amalya Lumerman Oliver, Lynne G. Zucker, and Marilynn B. Brewer, "Social Networks, Learning, and Flexibility: Sourcing Scientific Knowledge in New Biotechnology Firms, " Organization Science, February 1996, Z(1): in press.

3. Tolbert, Pamela S., and Lynne G. Zucker, "Institutionalization of Institutional Theory," in Stewart Clegg, Walter Nord, and Cynthia Harley, eds., Handbook of Organization Studies. London, England: Sage Publications, 1995 in press.

4. Zucker, Lynne G., Michael R. Darby, and Marilynn B. Brewer, "Intellectual Capital and the Birth of U.S. Biotechnology Enterprises, "National Bureau of Economic Research Working Paper No. 4653, February 1994.

5. Zucker, Lynne G., Michael R. Darby, and Jeff Armstrong, "Intellectual Capital and the Firm: The Technology of Geographically Localized Knowledge Spillovers, " National Bureau of Economic Research Working Paper No. 4946, December 1994.

6. Zucker, Lynne G., and Michael R. Darby, "Present at the Revolution: Transformation of Technical Identity for a Large Incumbent Pharmaceutical Firm after the Biotechnological Breakthrough, " National Bureau of Economic Research Working Paper No. 5243, August 1995. 
7. GenBank, Release 65.0, machine readable data base, Palo Alto, CA: IntelliGentics, Inc., September 1990.

8. Zucker, Lynne G., and Michael R. Darby, Report No. 2, Appendix A: Sociological Analysis of Multi-Institutional Collaborations in Space Science and Geophysics, AIP Study of Multi-Institutional Collaborations, Phase II: Space Science and Geophysics, College Park, MD: Center for History of Physics, American Institute of Physics, 1995 in press.

9. Zuckerman, Harriet, "Nobel Laureates in Science: Patterns of Productivity, Collaboration, and Authorship, "American Sociological Review, June 1967, 32(3): 391-403.

10. Zuckerman, Harriet, Scientific Elite: Nobel Laureates in the United States, New York: Free Press, 1977.

11. Cohen, Stanley, A. Chang, Herbert Boyer, and R. Helling, "Construction of Biologically Functional Bacterial Plasmids in vitro, "Proceedings of the National Academy of Sciences, 1973, 70: $3240-3244$.

12. Griliches, Zvi, "Hybrid Corn: An Exploration in the Economics of Technological Change," Econometrica, October 1957, 25(4): 501-522.

13. Nelson, Richard R., "The Simple Economics of Basic Scientific Research, "Journal of Political Economy, June 1959, 67(3): 297-306.

14. Arrow, Kenneth J., "Economic Welfare and the Allocation of Resources for Invention," in Richard R. Nelson, ed., The Rate and Direction of Inventive Activity: Economic and Social Factors, N.B.E.R. Special Conference Series vol. 13, Princeton, NJ: Princeton University Press, 1962. 
15. Arrow, Kenneth J., The Limits of Organization, New York, NY: W.W. Norton \& Company, 1974.

16. Nelson, Richard R., and Sidney G. Winter, An Evolutionary Theory of Economic Change, Cambridge, MA: Harvard University Press, 1982.

17. Rosenberg, Nathan, Inside the Black Box: Technology and Economics, Cambridge: Cambridge University Press, 1982.

18. Zucker, Lynne G., and Ita G.G. Kreft, "The Evolution of Socially Contingent Rational Action: Effects of Labor Strikes on Change in Union Founding in the 1880s, " in Joel A.C. Baum and Jitendra V. Singh, eds., Evolutionary Dynamics of Organizations, Oxford: Oxford University Press, 1994.

19. Wooldridge, Jeffrey M., "On the Application of Robust, Regression-Based Diagnostics to Models of Conditional Means and Conditional Variances," Journal of Econometrics, January $1991, \underline{47}: 5-46$.

20. Jones, Lyle V., Gardner Lindzey, and Porter E. Coggeshall, eds., An Assessment of Research-Doctorate Programs in the United States: Biological Sciences, Washington: National Academy Press, 1982.

21. Zucker, Lynne G., "Markets for Bureaucratic Authority and Control: Information Quality in Professions and Services, "Research in the Sociology of Organizations, 1991, $\underline{8}$ : 157189.

22. Griliches, Zvi, "The Search for R\&D Spillovers, " Scandinavian Journal of Economics, 1992 Supplement, 94: 29-47.

23. Romer, Paul M., "Increasing Returns and Long-Run Growth," Journal of Political Economy, October 1986, 94(5): 1002-1037. 
24. Romer, Paul M., "Endogenous Technological Change," Journal of Political Economy, 1990, 98 (5, Part 2--Supplement): S71-S102.

25. Grossman, Gene M., and Elhanan Helpman, Innovation and Growth in the Global Economy, Cambridge, MA: The MIT Press, 1991.

26. Eaton, Jonathan, and Samuel Kortum, "International Patenting and Technology Diffusion," National Bureau of Economic Research Working Paper No. 4931, November 1994.

27. Eaton, Jonathan, and Samuel Kortum, "Trade in Ideas: Patenting and Productivity in the OECD, " National Bureau of Economic Research Working Paper No. 5049, March 1995.

28. Acs, Zoltan J., and David B. Audretsch, "Innovation in Large and Small Firms: An Empirical Analysis, "American Economic Review, September 1988, 78: 678-690.

29. Acs, Zoltan J., and David B. Audretsch, "Innovation and Technological Change: The New Learning, "Advances in the Study of Entrepreneurship, Innovation, and Economic Growth, 1993, 6: 109-142.

30. Jaffe, Adam B., "Real Effects of Academic Research," American Economic Review, December 1989, 79: 957-970.

31. Jaffe, Adam B., Manuel Trajtenberg, and Rebecca Henderson, "Geographic Localization of Knowledge Spillovers as Evidenced by Patent Citations," Quarterly Journal of Economics, August 1993, 63: 577-598.

32. Acs, Zoltan, David B. Audretsch, and Maryann P Feldman, "R\&D Spillovers and Innovative Activity, "Managerial and Decision Economics, 1994, 15: 131-138.

33. Mansfield, Edwin, "Academic Research Underlying Industrial Innovations: Sources, Characteristics, and Financing, "Review of Economics and Statistics, February 1995, 77(1): $55-65$. 
34. Marshall, Alfred, Principles of Economics, 8th ed., London: Macmillan, 1920.

35. Audretsch, David B., and Maryann P Feldman, "The Geography of Innovation and Production, "in Centre for Economic Policy Research, The Location of Economic Activity: New Theories and Evidence, conference proceedings volume, Vigo, Spain: Consorcio de la Zona Franca di Vigo, 1993.

36. Head, K., Ries, J. \& Swenson, D. "Agglomeration Benefits and Location Choice: Evidence from Japanese Manufacturing Investment in the United States, "NBER Working Paper No. 4767, June 1994. .

37. Henkel, Mary, and Maurice Kagan, "Research Training and Graduate Education: ' The British Macro Structure, " in Burton R. Clark, ed., The Research Foundations of Graduate Education: Germany, Britain, France, United States, and Japan, Berkeley, CA: University of California Press, 1993, pp. 71-114.

38. Grossman, Gene M., and Elhanan Helpman, "Endogenous Innovation in the Theory of Growth," Journal of Economic Perspectives, Winter 1994, $\underline{8}(1):$ 23-44.

39. Jones, Charles I., "R\&D-Based Models of Economic Growth," Journal of Political Economy, August 1995, 103(4): 759-784.

40. Nelson, Richard R., and Edward N. Wolff, "Factors behind Cross-Industry Differences in Technical Progress," New York University Reports 92-27, June 1992.

41. Klevorick, Alvin K., Richard C. Levin, Richard R. Nelson, and Sidney G. Winter, "On the Sources and Significance of Interindustry Differences in Technological Opportunities," Research Policy, March 1995, 24(2): 185-205. 
42. Kogut, Bruce, Gordon Walker, Weijian Shan, and Dong-Jae Kim, "Platform Technologies and National Industrial Networks," in John Hagedoorn, ed., Internationalization of Corporate Technology Strategies, forthcoming 1994.

43. Levin, Richard C., "The Semiconductor Industry, "in Richard R. Nelson, ed., Government and Technological Progress: A Cross-Industry Analysis, New York: Pergamon Press, 1982.

44. Balkin, David B., and Luis R. Gomez-Mejia, "Compensation Practices in HighTechnology Industries, "Persónnel Administrator, June 1985, 111-123. 


\section{FOOTNOTES}

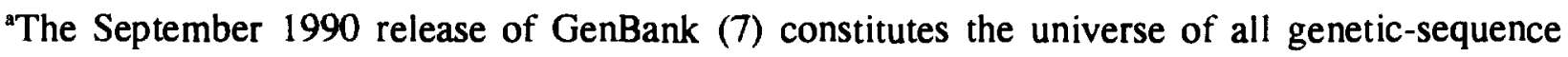
reporting articles through April 1990, from which we identified 327 stars worldwide, 4061 genetic-sequence-reporting articles, and 6082 collaborators, avoiding the more recent period during which sequencing has become more mechanical and thus not as useful an indicator of scientific activity. We coded the affiliations of each star and collaborator from the front (and back where necessary) pages of all 4061 articles authored by one or more stars to link in our relational data base to information on the employing universities, firms, research institutes and hospitals.

${ }^{b}$ Related results, reported under "Star Scientist Success and Ties to NBEs" below, demonstrate that these differences reflect primarily increased quality of work (measured by citations per article) while the star is affiliated or linked to a NBE.

'In the limit, where the discovery can be easily incorporated into the human capital of any competent scientist, the discoverer(s) cannot earn any personal returns -- as opposed to returns to intellectual property such as patents or trade secrets. In the case of biotechnology, it may be empirically difficult to separate intellectual capital from the conceptually distinct value of cell cultures created and controlled by a scientists who used his or her nonpublic information to create the cell culture.

${ }^{d}$ Not every social system, however, is flexible enough to rise to that demand. In work underway, we examine these processes comparatively across countries to explore both the demand and the aspects of the existing social structure that make realizing that demand difficult. In some countries, the social structure is just too costly to change, and great entrepreneurial opportunities are lost given the excellence of the bioscience. 


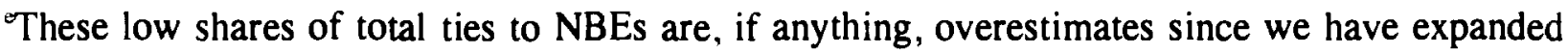
our definition of linked in Table 2 to include "foreign linked stars" whose only ties to NBEs are to firms outside their own country. NBSs have a higher share of links to these stars whose degree of connection to the firm is likely to be lower on average than local or other linked stars located in the same country as the NBE.

'Funding availability for coding products data and survey collection of additional employment data limited us to California for this analysis. With only 76 observations we limited our equation to a few main effects and did not attempt to estimate coefficients for other (or foreign) linkages. ${ }^{8}$ For various reasons related to the youth of the industry (5), it was not possible to use revenues, profits, or stock prices as measures of firm performance.

${ }^{\mathrm{b}}$ In our 110-NBE California sample, there are 87 NBFs and 22 NBSs (with one joint venture unclassified), a ratio that is only slightly higher than the national average.

These knowledge spillovers play a central role in the economics literature as causes of endogenous growth in recent "New Growth Theory Models" (22), though the empirical search for their existence has proved difficult (23-27), and in geographic agglomeration (local concentration) of particular industries. Recently, the fingerprints of spillovers have been found empirically as "geographically localized knowledge spillovers" by demonstrating statistically significant positive effects on a firm's productivity of being near great universities and other sources of scientific discovery (28-33). In model specifications not reported in Table 4 , we find that untied stars only appear significant as proxies of stars with ties in analyses where information on ties is suppressed, and even then only for products in development.

${ }^{j}$ We expected the linking relationship to be especially important, because of its potential for increasing information flow about important scientific discoveries made in the university into the NBE. Being part of an external "network for evaluation" these academic stars are likely to be 
able to provide more objective advice concerning scientific direction including which products should "die" before testing and marketing and which merit further investment by the firm, even given their often significant financial interest in the firm (21). Even so, we found the magnitude of the effects surprising.

${ }^{k}$ We believe, primarily on the basis of fieldwork, that very often tied stars were deeply involved in the formation of the NBEs to which they were tied. Moreover, we are beginning to examine some quantitative evidence which confirms our belief on the direction of causation. For star scientists whose publications began by the year of birth of the tied firm's birth, there is only an average lag of 3.02 years between the birth of the firm and the scientist's first tied publication, which is far shorter than the time required for any successful rDNA product to be approved for marketing (on the order of a decade). We would interpret most of the average lag in terms of time to set up a new lab, apply for patents on any discoveries, and then get into print, with some allowance needed for trailing agreements with prior or simultaneous employers. For star scientists who start publishing after the firm was born, the average lag between their first publication and their first tied publication is only 2.14 years. This is too short a career for the scientists to be hired for any possible halo effect. Indeed we think many of these scientists became stars only because of the very substantial productivity effects of working with NBEs. In summary, the evidence on timing is that these relationships typically start too early for either the firm to have any substantial track record or before the stars do.

'Examining other cases which occur with some frequency, we conclude that the simple case illustrates the main effects. We are indebted to our research assistant Kerry Knight for inventing this regression form.

${ }^{\mathrm{m}} \mathrm{We}$ are not yet distinguishing between local and non-local within country linkage in most countries; so we here define "linked" as referring to either form of coauthorship with a NBE- 
affiliated scientist from the same country as an academic star.

${ }^{n}$ We are extending our data base to 1994 to trace changes in this pattern of involvement in response to certain recent institutional and policy changes, particularly with respect to Japanese universities and research funding and removal of German regulatory restrictions on biotechnology. ${ }^{\circ}$ The low gross (in + out) migration rate reflects the large size of the U.S. market, so that there is much interregional but intranational migration with regional effects implicit in the analysis of birth of U.S. NBEs above.

${ }^{\mathrm{P} S e e}$, in particular, (6) for a detailed case study of the transformation of the technical identity of one of the largest U.S. pharmaceutical firms to the point that firm scientists and executives believe that it is indistinguishable in drug-discovery from the best large dedicated new biotech firms. A similar pattern of transformation appears to have been followed by about half of the large pharmaceutical firms. The remainder appear to be either gradually dropping out of drug discovery or merging with large dedicated new biotech firms to acquire the technical capacity required to compete.

${ }^{9}$ The economic infrastructure, including the flexibility of incumbent industries and the availability of start-up capital, is also likely to be significant in comparisons of international differences in commercialization of scientific breakthroughs. 
Table 1. U.S. stars' average annual citations by commercial ties \& patenting

Stars' gene-sequence patenting activity

Type of star

NBE affiliated*

Linked to a local $\mathrm{NBE}^{\dagger}$

Linked only to other U.S. NBE ${ }^{\ddagger}$

Never linked or affiliated

All stars

\begin{tabular}{|c|c|c|}
\hline No patents & Some patents & All Stars \\
\hline 153.2 & 549.2 & 323.0 \\
\hline 130.3 & 289.7 & 159.3 \\
\hline 100.1 & 176.8 & 109.4 \\
\hline 59.9 & 230.0 & 72.2 \\
\hline 77.3 & 310.9 & 104.4 \\
\hline
\end{tabular}

The values are the total number of citations in the Science Citation Index for the 3 years 1982, 1987, 1992 for all genetic-sequence discovery articles (up to April 1990) in GenBank (7) authored or coauthored by each of the stars in the cell divided by 3 (years) times the number of stars in the cell.

*All stars ever affiliated with a U.S. new biotechnology enterprise (NBE).

${ }^{\dagger}$ Any other star ever coauthoring with scientists from NBE in same BEA area.

${ }^{\ddagger}$ Any other star ever coauthoring with scientists from NBE outside BEA area.

${ }^{8}$ All remaining stars who ever published in the U.S. 
Table 2. Articles by affiliated or linked stars

\begin{tabular}{|c|c|c|c|c|c|}
\hline \multicolumn{2}{|l|}{ NBEs } & \multicolumn{4}{|c|}{ Article counts of stars } \\
\hline & & \multirow{2}{*}{$\begin{array}{l}\text { Affil- } \\
\text { iated* }\end{array}$} & \multirow{2}{*}{$\begin{array}{l}\text { Local } \\
\text { linked }\end{array}$} & \multirow{2}{*}{$\begin{array}{l}\text { Other } \\
\text { linked }\end{array}$} & \multirow{2}{*}{$\begin{array}{l}\text { Forelgn } \\
\text { linked }\end{array}$} \\
\hline Type by pertod & No. & & & & \\
\hline \multicolumn{6}{|l|}{$1976-1980$ : } \\
\hline NBFs & 1 & 9 & 0 & 0 & 0 \\
\hline Major Pharm. NBSs & 0 & 0 & 0 & 0 & 0 \\
\hline Other NBSs & 0 & 0 & 0 & 0 & 0 \\
\hline Total All NBEs & 1 & 9 & 0 & 0 & 0 \\
\hline \multicolumn{6}{|l|}{$1981-1985:$} \\
\hline NBF $\mathbf{g}$ & 13 & 97 & 20 & 12 & 10 \\
\hline Major Pharm. NBSs & 4 & 0 & 2 & 7 & 1 \\
\hline other NBSs & 0 & $\quad \mathbf{0}$ & 0 & 0 & 0 \\
\hline Total All NBEs & 17 & 97 & 22 & 19 & 11 \\
\hline \multicolumn{6}{|l|}{$1986-1990:$} \\
\hline NBFs & 19 & 68 & 16 & 30 & 6 \\
\hline Major Pharm. NBSs & 8 & 8 & 3 & 9 & 4 \\
\hline Other NBSs & 3 & 0 & 2 & 2 & 0 \\
\hline Total All NBEs & 30 & 76 & 21 & 41 & 10 \\
\hline \multicolumn{6}{|l|}{$1976-1990$ : } \\
\hline NBF 8 & 22 & 174 & 36 & 42 & 16 \\
\hline Major Pharm. NBSs & 9 & 8 & 5 & 16 & 5 \\
\hline Other NBSs & $\begin{array}{r}3 \\
34\end{array}$ & $\begin{array}{r}0 \\
182\end{array}$ & $\begin{array}{r}2 \\
43\end{array}$ & $\begin{array}{r}2 \\
60\end{array}$ & $\begin{array}{r}0 \\
21\end{array}$ \\
\hline Total All NBEg & & & & & 21 \\
\hline
\end{tabular}

* Count of articles published by each star affiliated with a U.S. NBE of indicated type during the period. ${ }^{+}$Count of articles published by each O.S. star linked to a NBE in the same BEA by type se period.

* Count of articles published by each U.S. star linked to a NBE in a different BEA by type 2 period.

'Count of articles published by each foreign star linked to a U.S. NBE by type s period. 
Table 3. Poisson Regressions: Births of NBEs, 1976-89

\begin{tabular}{|c|c|c|c|}
\hline Variables & \multicolumn{3}{|c|}{ Coefficients (Standard Errors) } \\
\hline 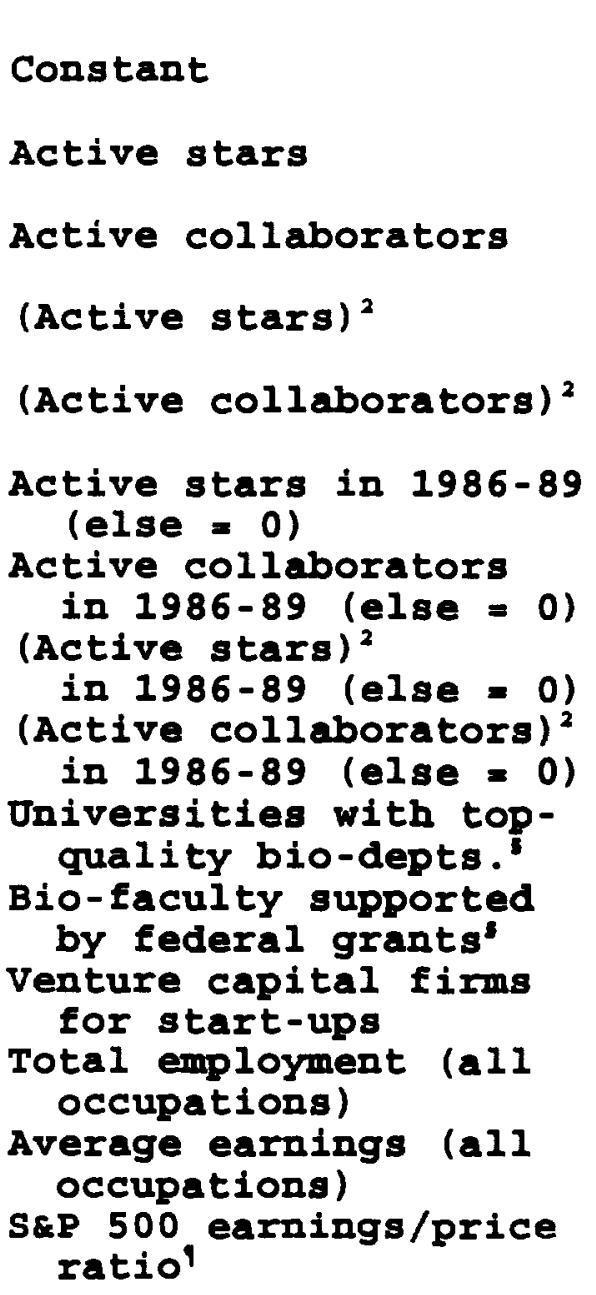 & $\begin{array}{c}\text { model } \\
-2.086^{*} \\
(.0538) \\
0.294^{*} \\
(.0809) \\
0.025 \\
(.0461) \\
-0.015^{\circ} \\
(.0054) \\
.0004 \\
(.0014) \\
-0.243 * \\
(.1098) \\
0.139 * \\
(.0642) \\
0.007 \\
(.0064) \\
-0.002 \\
(.0017) \\
0.406^{*} \\
(.1161) \\
0.619^{*} \\
(.0871)\end{array}$ & $\begin{array}{c}0.017^{\prime} \\
(.0062) \\
0.186^{*} \\
(.0474) \\
0.145^{*} \\
(.0103) \\
-0.026 \\
(.0162)\end{array}$ & $\begin{array}{c}\text { model c } \\
-4.177^{*} \\
(.3145) \\
0.384^{*} \\
(.0729) \\
-0.011 \\
(.0432) \\
-0.016^{*} \\
(.0046) \\
0.001 \\
(.0014) \\
-0.314^{\dagger} \\
(.0962) \\
0.141^{*} \\
(.0595) \\
0.010 \\
(.0053) \\
-0.002 \\
(.0016) \\
0.431^{*} \\
(.0908) \\
0.943^{*} \\
(.0891) \\
-0.028^{*} \\
(.0054) \\
-0.064 \\
(.0441) \\
0.109^{*} \\
(.0148) \\
-0.018 \\
(.0241)\end{array}$ \\
\hline $\begin{array}{l}\text { Log-likelihood } \\
\text { Log-likelihood coefs. }=0\end{array}$ & $\begin{array}{l}-1310.2 \\
-2189.8\end{array}$ & $\begin{array}{l}-1666.4 \\
-2189.8\end{array}$ & $\begin{array}{l}-1249.0 \\
-2189.8\end{array}$ \\
\hline
\end{tabular}

All variables are counts for the BEA area and year of observation $(N=2562)$ except as noted. Standard errors adjusted by Wooldridge's Procedure 2.1 (19) are in parentheses below coefficients.

Probability $|t-s t a t|>x: *<.05,+<.01, *<.001$

SVariable value circa 1980 (20) is used for all years.

'Variable value for current year is used all BEA areas. 
Table 4. Regressions explaining NBE success: California

\begin{tabular}{|c|c|c|c|}
\hline ariables & oeffic: & $s \quad$ (St & d Errors \\
\hline $\begin{array}{l}\text { Constant } \\
\text { Count of articles by } \\
\text { stars untied to NBE } \\
\text { Count by articles by } \\
\text { NBE-linked stars } \\
\text { Count of articles by } \\
\text { NBE-affiliated stars } \\
\text { Dummy = } 1 \text { if NBF (NBE } \\
\text { born > } 1975 \text { ), else } 0 \\
\text { Years from entry into } \\
\text { biotech to } 1989 \text { (age) } \\
\text { Dumy = } 1 \text { if NBE uses } \\
\text { rDNA, else } 0 \\
\text { Inverse Mills ratio } \\
\text { (selectivity correc.) } \\
\text { Log-likelihood } \\
\text { Log-likelihood coefs. =0 }\end{array}$ & $\begin{array}{l}\text { prods. } \\
\text { develop. } \\
-1.9324^{*} \\
(0.2796) \\
0.0001 \\
(0.0003) \\
0.3197^{*} \\
(0.0161) \\
0.0006 \\
(0.0010) \\
1.3417^{*} \\
(0.1455) \\
0.1209^{*} \\
(0.0191) \\
0.2845^{*} \\
(0.1278) \\
n / a \\
-169.46 \\
-255.28\end{array}$ & $\begin{array}{l}\text { prods } \\
\text { market } \\
1.4953^{*} \\
(0.1085) \\
-0.0006^{*} \\
(0.0002) \\
0.1143^{*} \\
(0.0140) \\
0.0024^{*} \\
(0.0006) \\
-0.3512^{*} \\
(0.0733) \\
0.0643^{*} \\
(0.0088) \\
-0.5880^{*} \\
(0.0567) \\
n / a \\
-296.20 \\
-323.14\end{array}$ & $\begin{array}{c}\text { employmen } \\
\text { growth' } \\
51.022 \\
(252.53) \\
-0.7130 \\
(0.4256) \\
172.17^{\dagger} \\
(78.157) \\
-4.3847 \\
(4.7782) \\
-225.45 \\
(163.82) \\
36.439 \\
(22.719) \\
267.78 \\
(131.56) \\
166.33^{\prime} \\
(74.189) \\
n / a^{i} \\
n / a^{1}\end{array}$ \\
\hline
\end{tabular}

All variables are for individual California NBEg responding to a telephone census on employment in 1994 (N $=76$ ) except as noted. Standard errors are in parentheses below coefficients. Probability $\mid t$-stat $\mid>x: \star \leq 0.10,+\leq 0.05, \quad \leq 0.01$ 'Poisson regression for counts of the NBE' $s$ products in development or on the market in 1990 , standard errors are adjusted by Wooldridge's Procedure 2.1 (19).

'Second-stage Heckman estimates for non-zero 1989-94 employment change observations with consistent variance-covariance matrix estimates (5); inverse Mills ratio is correction for selectivity (or response) bias for NBEs reporting no change from 1989; adjusted $R^{2}=0.1623$. 
Table 5. Total citations to articles by stars

\begin{tabular}{|c|c|c|}
\hline Variables & Coeffs. & td. Exr.) \\
\hline 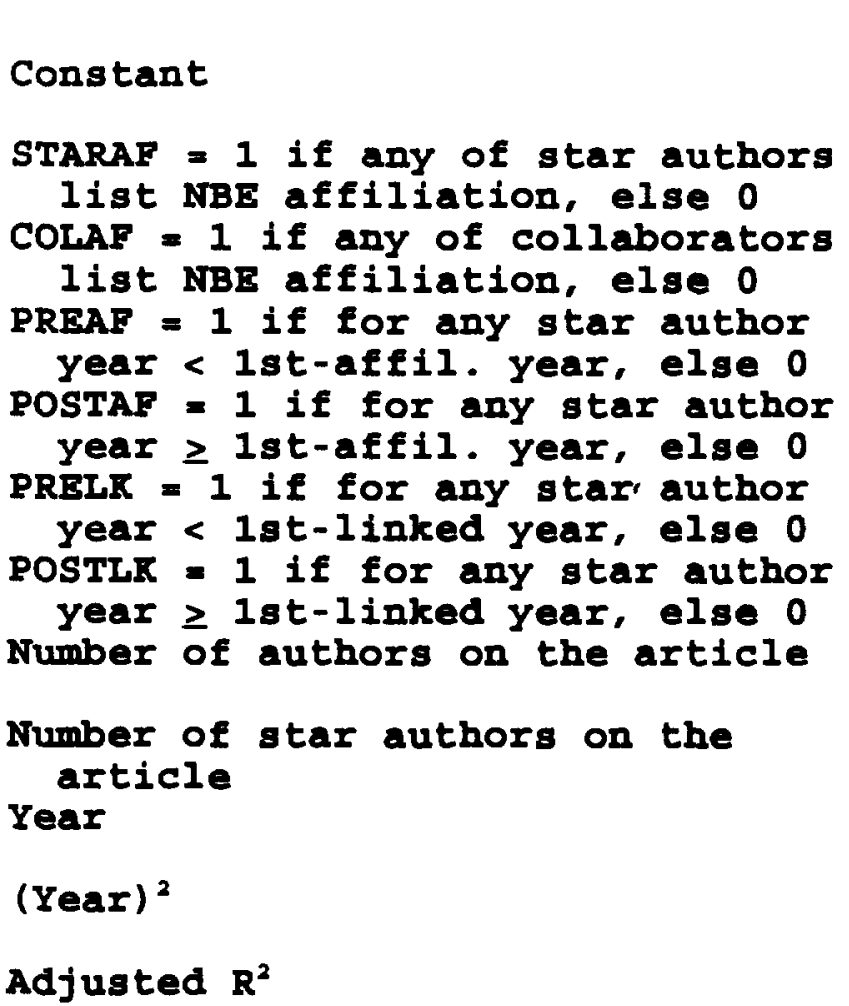 & $\begin{array}{c}\text { world } \\
-31.676^{*} \\
(6.092) \\
17.671^{*} \\
(4.024) \\
7.626^{*} \\
(2.428) \\
-1.983 \\
(2.257) \\
-3.114 \\
(2.844) \\
4.285^{*} \\
(1.175) \\
-3.114 \\
(2.844) \\
2.227^{*} \\
(0.203) \\
2.519^{*} \\
(0.679) \\
4.994^{*} \\
(0.727) \\
-0.176^{*} \\
(0.022) \\
0.106\end{array}$ & $\begin{array}{c}\text { US Only } \\
-42.789^{*} \\
(9.536) \\
20.915^{*} \\
(7.076) \\
5.254 \\
(3.585) \\
3.661 \\
(4.362) \\
-6.644 \\
(5.943) \\
1.378 \\
(1.702) \\
-0.514 \\
(1.731) \\
3.062 * \\
(0.340) \\
0.942 \\
(1.095) \\
6.707^{*} \\
(1.112) \\
-0.229^{*} \\
(0.033) \\
0.133\end{array}$ \\
\hline
\end{tabular}

All variables refer to the authors and publication date of each of the articles authored by 1 or more stars.

Probability $|t-s t a t|>x: *<.05,+<.01, *<.001$ 
Table 6. National starg: commercial ties migration

\begin{tabular}{lcllr}
\hline & $\begin{array}{l}\text { Share of } \\
\text { Stars* }\end{array}$ & $\begin{array}{l}\text { Fraction } \\
\text { tied }^{*}\end{array}$ & \multicolumn{2}{c}{ Migration Rate } \\
Gross & Net $^{*}$ \\
United states & 50.2 & 33.3 & 22.2 & 2.9 \\
Japan & 12.6 & 21.1 & 40.4 & 9.6 \\
United Kingdom & 7.5 & 9.7 & 58.1 & -32.3 \\
France & 6.1 & 0.0 & 20.0 & 4.0 \\
Germany & 5.8 & 0.0 & 50.0 & 8.3 \\
Switzerland & 3.6 & 20.0 & 93.3 & -40.0 \\
Australia & 3.4 & 7.1 & 35.7 & 7.1 \\
Canada & 2.4 & 0.0 & 50.0 & -30.0 \\
Belgium & 1.7 & 14.2 & 42.9 & 14.3 \\
Netherlands & 1.2 & 20.0 & 80.0 & 0.0 \\
Total for top 10 & 94.7 & 14.9 & 35.4 & -0.8
\end{tabular}

*\% of total stars ever publighing in any country; some doublecounting of multiple-country stars; rest of world: Denmark, Finland, Israel, Italy, Sweden U.S.S.R.

if of stars ever publishing who were affiliated or linked to a NBE in the country.

\$100 x (Immigration + emigration of stars)/stars ever publishing in country.

'100 x (Immigration - emigration of stars)/stars ever publishing in country. 


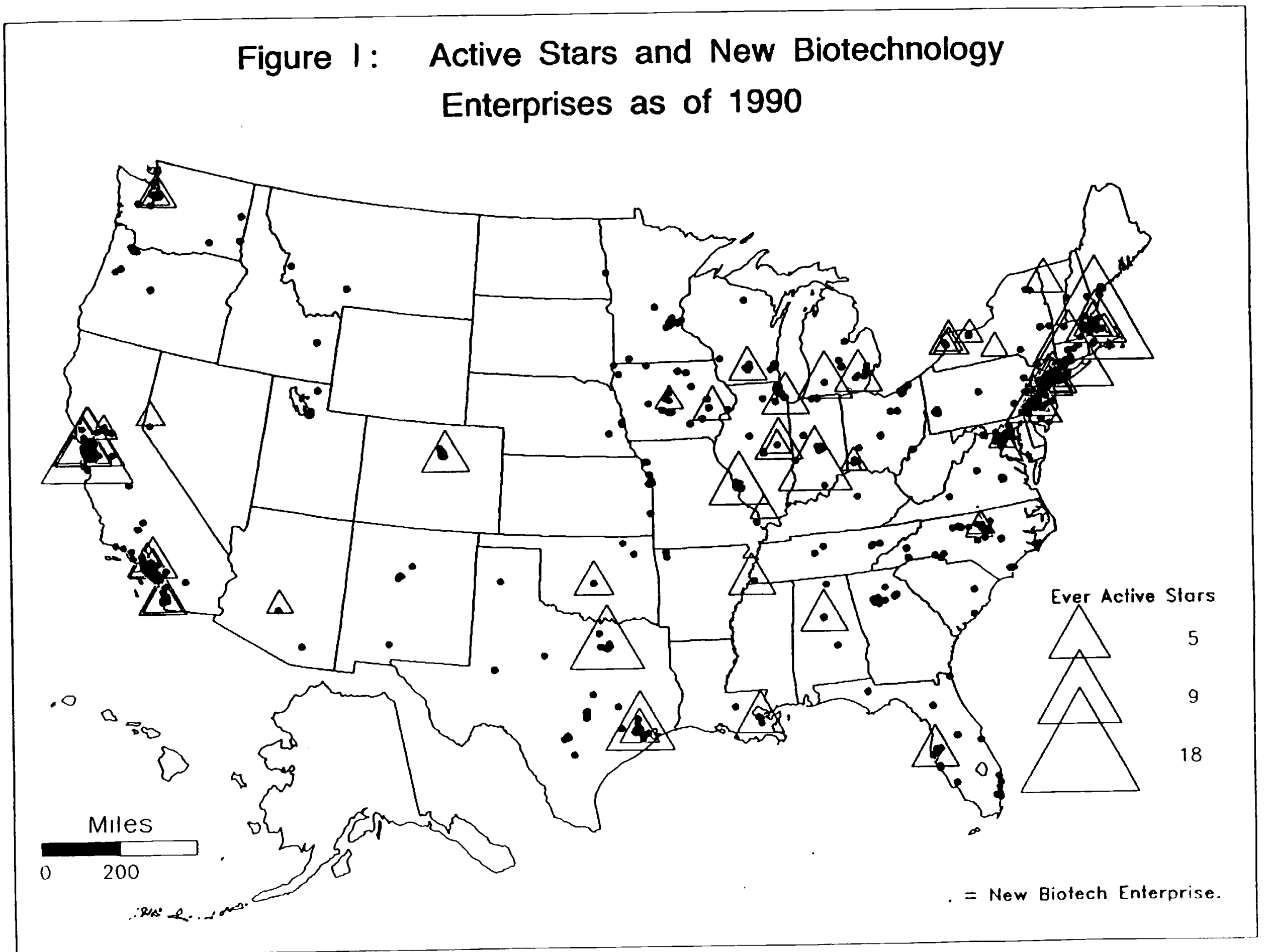


Figure 2: California Stars and Products in Development at NBEs

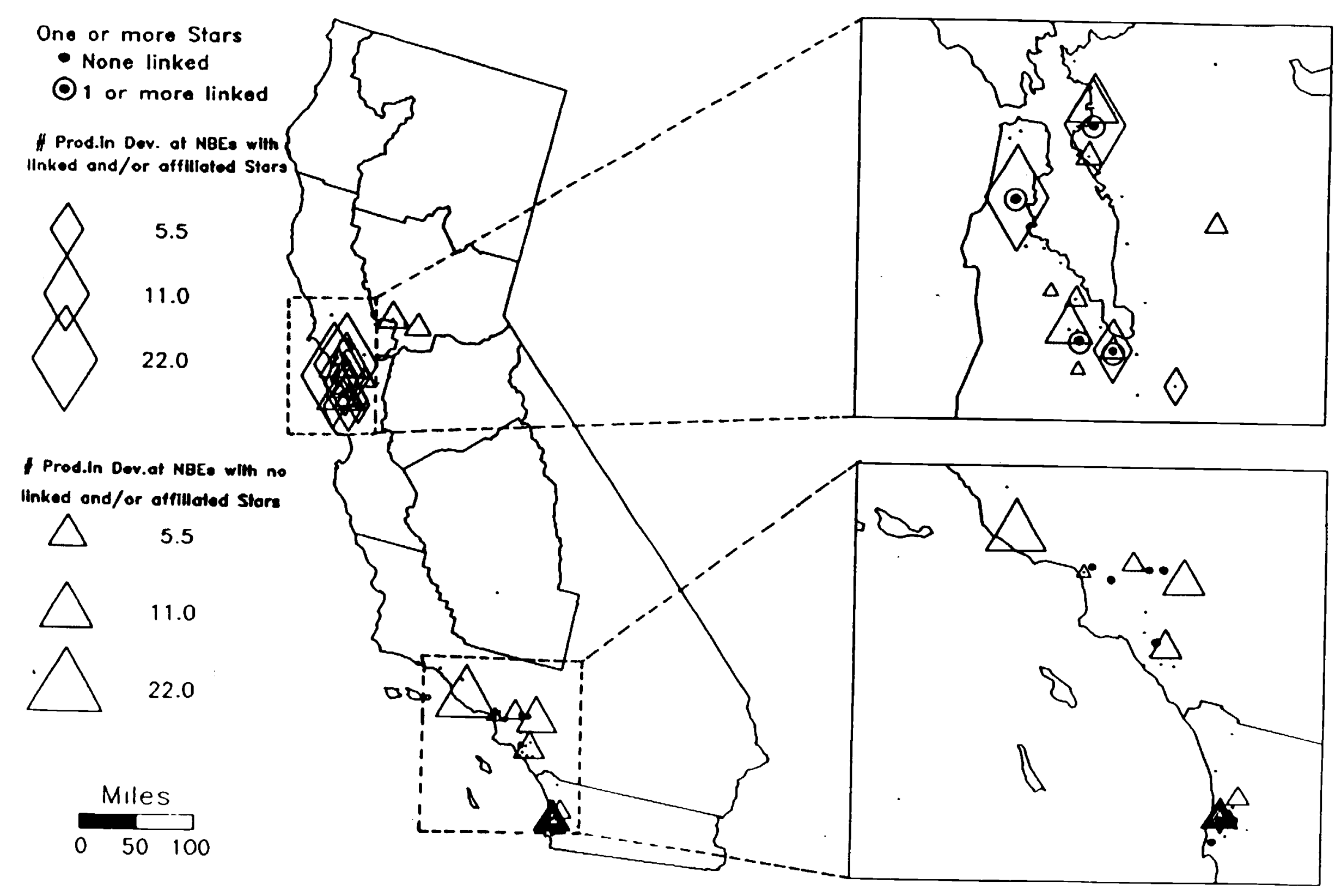

